\title{
Resenha de Vozes do Bolsa Família: Autonomia, dinheiro e cidadania, de Walquiria Leão Rego e Alessandro Pinzani (São Paulo: Editora Unesp, 2013)
}

\author{
Rúrion Melo \\ rurionsm@hotmail.com \\ (Universidade de São Paulo, São Paulo, Brasil)
}

DOI: http://dx.doi.org/10.11606/issn.2318-9800.v19i1p213-221

Todos aqueles preocupados com o crescimento econômico, melhora nas condições de vida e diminuição das desigualdades no Brasil deveriam reconhecer os impactos decisivos de certos programas redistributivos sobre a sociedade brasileira, em particular os programas de transferência direta de renda iniciados como estratégia de combate à desigualdade nos anos do governo $\mathrm{FHC}$, mas sensivelmente intensificados durante o governo Lula. ${ }^{1}$ O Programa Bolsa Família (BF), caracterizado como um programa de transferência direta de renda que procura beneficiar famílias em situação de pobreza e de extrema pobreza em todo país, certamente se destaca neste rol de políticas compensatórias. ${ }^{2}$ Porém, muita dúvida tem sido lançada quanto à eficácia e à justificação normativa deste programa. De que maneira podemos compreender o sentido de tal programa no âmbito de um projeto moderno de sociedade? E como medir suas consequências econômicas e sociais na vida de seus concernidos? Gostaria de refletir um pouco sobre tais questões tomando por base a interessante pesquisa publicada por Walquiria Leão Rego e Alessandro Pinzani em seu recente livro Vozes do Bolsa Familia: Autonomia, dinheiro e cidadania.

Assumo de início junto com os respectivos autores a ideia de que o BF precisa ser compreendido de um ponto de vista crítico amplo que

1. Cf. MEDEIROS, M.; BRITTO, T.; SOARES, F. Transferência de renda no Brasil. Novos Estudos - CEBRAP, n. 79, 2007, pp. 5-21; MEDEIROS, M.; SOARES, F. V.; SOARES, S.; OSÓRIO, R. G. Programas de transferência de renda no Brasil: Impactos sobre a desigualdade. Brasília: IPEA, 2006.

2. Para uma visão abrangente em relação ao Programa Bolsa Família, cf. SILVA, M. O. S.; LIMA, V. F. S. A. (Orgs.). Avaliando o Bolsa Família: unificação, focalização e impactos. São Paulo: Cortez, 2011; CASTRO, J. A.; MODESTO, L. (Orgs.). Bolsa Família 2003-2010: Avanços e desafios. Brasília: IPEA, 2010. 
diz respeito às pretensões próprias de desenvolvimento, modernização e democratização do país. O programa tem um alvo principal que é o combate à pobreza, mas seus efeitos e condicionalidades são imensos, revelando assim um potencial importante para uma série de transformações sem as quais a promessa de um país moderno e democrático não poderia ser cumprida nas condições atuais: seus impactos atingem não apenas a camada pobre e menos favorecida da população em geral, mas mais precisamente as relações de gênero e suas consequências, tais como a estrutura familiar, o escasso horizonte educacional dos filhos, os déficits nutricionais das crianças e a inclusão cívico-política dos beneficiários. Efeitos consideráveis, sem dúvida, em um país dito desenvolvido, moderno e democrático, mas que convive com extrema desigualdade econômica e social, exclusão política, preconceito regional, racial e de gênero, e violação sistemática de direitos humanos, ou seja, a realidade de milhões de brasileiros que ainda estão "completamente fora das heranças mais básicas da civilização" (p. 15).

Nesse sentido, Vozes do Bolsa Família parte de uma cobrança inerente à nossa própria história política. Não deveríamos avaliar os efeitos dos programas redistributivos com a ótica da experiência europeia e americana, por exemplo. Sabe-se que desde pelos menos 1970 foram levados a cabo diversos diagnósticos sobre as crises dos modelos keynesianos e de bem-estar social. ${ }^{3}$ No caso brasileiro, mais precisamente a partir de 1988 (isto é, após o período do "nacional-desenvolvimentismo"), vislumbramos, pelo contrário, a possibilidade de concretizar a esperança de um Estado social democrático, um projeto de desenvolvimento econômico que não fosse desprovido de um "projeto democrático substantivo" (p. 159). ${ }^{4} \mathrm{Na}$ qualidade de

3. Cf. O'CONNOR, J. The Fiscal Crisis of the State. New Brunswick/London: Transaction Publishers, 2002, HABERMAS, J. Legitimationskrise im Spätkapitalismus. Frankfurt am Main: Suhrkamp, 1973; CASTEL, R. As metamorfoses da questão social: Uma crônica do salário. Trad. de Iraci Poleti. Petrópolis: Vozes, 2009.

4. Marcos Nobre sugeriu recentemente o termo "social-desenvolvimentismo" para sublinhar um novo modelo de sociedade consolidado (mas não plenamente realizado) a partir do período de redemocratização do Brasil. "Segundo o novo modelo, só é desenvolvimento autêntico aquele que é politicamente disputado segundo o padrão e o metro do social, quer dizer, aquele em que a questão distributiva, em que as desigualdades - de renda, de poder, de recursos ambientais, de reconhecimento social — passam para o centro da arena política como o ponto de disputa fundamental" (NOBRE, M. Imobilismo 
marco determinante de nossa história política recente, a Constituição de 1988 "enuncia um projeto de país e de sociedade" (p. 162), sublinhando a gênese democrática representada pelas demandas das lutas sociais incorporadas à Constituição, sobretudo no que concerne ao tema da "justiça distributiva" assumida então como um "elemento vinculante de todo o sistema normativo" (p. 165).

Mas não é só isso. Walquiria Leão Rego e Alessandro Pinzani dão um passo além na medida em que escolhem explicitar um ponto de referência normativo interno aos próprios processos que pretendem investigar e avaliar. Nosso desenvolvimento político permite ser questionado, ademais, do ponto de vista do "projeto da modernidade" por excelência. Tal projeto consiste na "promessa de autonomia (individual e coletiva)" (p. 55-56), uma promessa que a própria modernidade faz e não cumpre por razões que lhes são imanentes. Esse é um déficit específico, portanto, da sociedade capitalista contemporânea, a saber, "prometer autonomia para todos e não lhes oferecer as condições reais (e não meramente formais) para desenvolvê-la" (p. 56).

Um dos aspectos peculiares da abordagem teórica proposta no livro está voltado, assim, à investigação dos efeitos morais e políticos sobre os beneficiários do programa tendo em vista mais precisamente uma concepção de autonomia individual baseada, segundo os autores, no capability approach desenvolvido por Amartya Sen e Martha Nussbaum. ${ }^{5}$ Trata-se de entender antes de tudo de que maneira uma reflexão normativa sobre a autonomia individual dependeria crucialmente das oportunidades reais que a pessoas possuem para usufruir com liberdade de suas próprias vidas. $\mathrm{E}$ o $\mathrm{BF}$, ao atender às dificuldades das pessoas em pior situação de pobreza, toca justamente nas capacidades e oportunidades reais de seus beneficiários.

Sendo assim, o BF poderia ajudar na realização do projeto moderno brasileiro concernente à promessa de autonomia? A resposta dos autores é sim, se entendermos o conceito de autonomia de deter-

em movimento: Da abertura democrática ao governo Dilma. São Paulo: Companhia das Letras, 2013, p. 24).

5. Cf. NUSSBAUM, M. Women and Human Development: The Capabilities Approach. Cambridge, ma: Cambridge University Press, 2000; NUSSBAUM, M, Creating Capabilities. The Human Development Approach. Cambridge, ma: Belknap, 2011; SEN, A. Desenvolvimento como liberdade. São Paulo: Companhia das Letras, 2000; SEN, A. A ideia de justiça. São Paulo: Companhia das Letras, 2011. 
minada maneira: "Atribuímos autonomia a um sujeito quando ele é capaz de agir conforme um projeto pessoal de vida boa [...] e de considerar a si e a outros sujeitos como capazes de estabelecer relações de direitos e deveres" (p. 57). Em outros termos, o BF pode "oferecer condições reais (e não meramente formais)" para que a modernidade cumpra sua promessa. "Somos da opinião", afirmam os autores, "de que um programa como o BF se insere justamente nesse contexto e que seu efeito primário, além de garantir a subsistência imediata, é o de fornecer uma base material necessária para que os indivíduos possam desenvolver-se em direção a uma maior autonomia" (p. 69).

O interessante é que, ao falarmos da "autonomia" como categoria normativa, não estamos assumindo a centralidade desta categoria de fora dos contextos éticos, sociais e políticos correspondentes. Os efeitos colaterais provocados pela pobreza no Brasil não são avaliados apenas em termos objetivos e, principalmente, institucionais. Ao assumir um ponto de vista ético a partir do qual é possível ancorar uma teoria crítica da sociedade (p. 24-27), salta à vista o sofrimento, humilhação e desrespeito frequentes experimentados pelas pessoas em situação de injustiça. ${ }^{6}$ As condições objetivas da pobreza criam patologias diagnosticadas no quadro dos sentimentos pessoais, resultantes, entre outras coisas, da falta de acesso à renda regular, das dificuldades para a manutenção de uma vida minimamente saudável e da exclusão da cidadania. Assim, quando ouvimos as vozes dos excluídos e dos "invisíveis" (propósito da pesquisa, aliás), salta à vista a injustiça moral vivida pelas pessoas que carecem de um grau mínimo de autonomia. Deste modo, identificada essa forma de patologia individual causada pela realidade objetiva do mundo econômico e social, é possível então avaliar as consequências positivas e/ou negativas do programa do BF sobre a constituição de elementos básicos da autonomia moral individual, ou seja, investigar até que ponto políticas redistributivas desse

6. Cf. a abordagem sobre as bases sociais e morais da experiência de "injustiça" em MOORE Jr., B. Injustiça: As bases sociais da obediência e da revolta. Trad. de João Roberto M. Filho. São Paulo: Brasiliense, 1987. De maneira semelhante, ver MILLER, D. Principles of Social Justice. Cambridge, ma: Harvard University Press, 2001. Cf. também HONNETH, A. Philosophie als Sozialforschung. Zur Gerechtigkeitstheorie von David Miller. In: Das Ich im Wir. Berlin: Suhrkamp, 2010, e ANDERSON, J.; HONNETH, A., A. Autonomia, Vulnerabilidade, Reconhecimento e Justiça. Tradução de Nathalie Bressiani. Cadernos de Filosofia Alemã : Crítica e Modernidade, n. 17, 2011, pp. 81-112. 
tipo são capazes de fornecer as bases materiais para a formação de um projeto independente de vida boa e de relações morais concernentes a direitos e deveres, com o propósito de possibilitar a dignidade e o autorrespeito dos membros da sociedade que se encontram vivendo sob condições de pobreza e miséria.

Para tanto, é preciso ainda mostrar que o BF pressupõe uma correlação fundamental entre "renda em dinheiro" e "autonomia individual". Aliás, eu arriscaria dizer que essa é a tese central do livro, segundo a qual "a presença de uma renda monetária regular", ainda que reconhecidamente insuficiente, "permite o desencadeamento de processos de autonomização individual em múltiplos níveis" (p. 38). "Múltiplos níveis", já que o recebimento da renda em dinheiro produz importantes efeitos na autorrealização e autodeterminação de seus beneficiários, criando as condições sociais reais básicas para os dois aspectos normativos da autonomia trabalhados pelos autores: a autonomia moral individual e a autonomia cidadã (o desenvolvimento de uma percepção de si como membro de uma comunidade política mais ampla). Em outros termos, a pesquisa mostra que o recebimento da renda monetária regular traz consigo transformações éticas, sociais e políticas imprescindíveis. Muito mais do que garantia mínima à manutenção da vida, o dinheiro, dessa perspectiva, tem antes um efeito desreificante, que, entre outras coisas, desnaturaliza as relações patriarcais dominantes e dá início a processos de libertação das mulheres diante do controle masculino familiar. "O recebimento da renda monetária", afirmam os autores, "trouxe para muitas mulheres um elemento decisivo: a dignificação das suas pessoas como sentimento

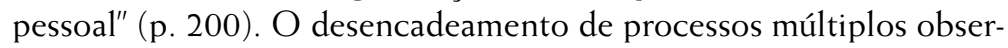
vado em termos de autonomia implica, na verdade, desde a capacidade individual do sujeito de fazer escolhas, passando pelo sentimento moral de governar sua própria vida, se responsabilizar pelas próprias ações e ser capaz de cuidar de si e da família, até a autopercepção de ser considerado pelo próprio Estado como membro de uma comunidade política, seu reconhecimento como cidadão.

Sem dúvida, não é uma tarefa fácil fundamentar tal tese, isto é, mostrar os múltiplos níveis da relação entre dinheiro e autonomia. Por essa razão, é digno de atenção o esforço empreendido por Walquiria Leão Rego e Alessandro Pinzani para mobilizar tantos elementos, construindo de maneira criativa, por assim dizer, os referenciais metodológicos e normativos da pesquisa: o propósito interdisciplinar de realizar uma pesquisa social com pontos de vista crítico-normativos 
(fazendo dialogar filosofia e sociologia), mesclar dados empíricos com entrevistas (dando primazia às análises qualitativas), realizar um balanço bibliográfico extenso e atual. Embora reconheçam que a pesquisa não foi exaustiva, pode-se ver nela os indícios empíricos do papel libertador da renda em dinheiro, ancorados na interpretação complexa, delicada e, antes de tudo, experimental dos efeitos do programa sobre as subjetividades das mulheres.

O programa BF apresenta assim muitos ganhos. Não podemos menosprezar seu impacto real na vida das famílias. Mas de modo algum podemos negligenciar seus efeitos colaterais, pois é também certo que existem dificuldades. Algumas críticas internas ressaltam, com mais ou menos razão, a ambivalência presente ao longo de sua implementação. Para alguns, enquanto programa de transferência direta de renda, o BF poderia ser radicalizado. ${ }^{7}$ Deveríamos também atentar para o impacto local muito diferenciado. ${ }^{8}$ Pesquisas sobre evasão escolar, por exemplo, mesmo apontando sucesso, explicitam ainda uma grande desigualdade regional. ${ }^{9}$ Além disso, certas críticas mais contundentes ao programa são feitas por parte do próprio discurso feminista: embora o BF possua um recorte explícito de gênero, o programa estaria paradoxalmente cristalizando o papel da mulher no sistema reprodutivo e produziria efeitos adversos relacionados à participação no mercado de trabalho (já que o programa estimularia a mulher a continuar em casa cuidando dos filhos). ${ }^{10}$

7. Cf. SUPLICY, E. M. O direito de participar da riqueza da nação: do Programa Bolsa Família à Renda Básica de Cidadania. Ciência \& Saúde Coletiva, v. 12, n. 6, 2007, p. 1623-1628. Cf. ainda a nova edição de SUPLICY, E. M., Renda de cidadania: A saída é pela porta. São Paulo: Cortez, 2013.

8. Cf. ROCHA, S. O Programa Bolsa Família. Evolução e efeitos sobre a pobreza. Economia e sociedade, v. 20, n. 1, 2011, pp. 113-139.

9. Cf. AMARAL, E. F. L.; MONTEIRO, V. P. Avaliação de impacto das condicionalidades de educação do Programa Bolsa Família (2005-2009). Dados, v. 56, n. 3, 2013, pp. 531-570; CACCIAMALI, M. C.; TATEI, F.; BATISTA, N. F. Impactos do Programa Bolsa Família federal sobre o trabalho infantil e a frequência escolar. Revista de economia contemporânea, v. 14, n. 2, 2010, pp. 269-301.

10. Cf. MARIANO, S. A.; CARlOTO, C. M. Gênero e Combate à Pobreza: Programa Bolsa Família. Revista Estudos Feministas, v. 17, n. 3, 2009, p. 901-8; GOMES, S. S. R. Notas preliminares de uma crítica feminista aos programas de transferência direta de renda: o caso do Bolsa Família no Brasil. Textos \& 
Podemos aliar a tais aspectos internos o problema segundo o qual, em termos de diagnóstico mais geral, o reformismo, absolutamente necessário no Brasil, é ambíguo. Avançamos lentamente. Pois nosso "reformismo fraco", para usar um termo empregado por André Singer, caracteriza-se basicamente pelo fato de que a redução das desigualdades no Brasil (impulsionada, vale dizer, não somente pela política redistributiva, mas pelo aumento do emprego e da renda durante o governo Lula), ocorre em doses homeopáticas. ${ }^{11} \mathrm{O}$ horizonte verdadeiramente democrático de expectativas, potencialmente presente no BF, deveria antes ser ampliado: o "reformismo fraco" tem de ser empurrado até o ponto em que permita vincular de fato autonomia individual e política, pois o que queremos é ver realizada a ideia normativa de um enraizamento do Estado de direito na vontade dos cidadãos. Mas sem ampla redistribuição, sem medidas extremas de combate à pobreza, à desigualdade e à injustiça, só aumentamos os obstáculos que se impõem no caminho de consolidação de uma sociedade digna de ser considerada democrática.

Os autores de Vozes do Bolsa Família estão conscientes que a tese do "relativo empoderamento" das mulheres realizado pelo dispositivo de transferência direta de renda guarda dimensões ambíguas e paradoxais. Ainda assim, afastando nosso olhar de aspectos predominantemente econômicos (para não falar de preconceitos e estereótipos comuns assumidos por boa parte da opinião pública quando se trata de falar do BF ou de políticas redistributivas em geral), os autores nos deixam ver um entrelaçamento que não pode passar despercebido entre a pobreza e o sentimento pessoal ligado ao autorrespeito, às capabilitties e à autonomização. Daí a importância de uma pesquisa que nos debruce no cotidiano, subjetividades, hábitos e expectativas das mães de famílias beneficiadas, de modo a darmos ouvido às suas vozes. A humilhação, o sofrimento e o desrespeito são vulnerabilidades objetivamente produzidas que precisam ser politicamente sanadas. Por

Contextos. Porto Alegre, v. 10, n. 1, 2011, p. 69-81; TAVARES, P. A. Efeito do Programa Bolsa Família sobre a oferta de trabalho das mães. Economia e sociedade, v. 19, n. 3, 2010, p. 613-35.

11. "O que estamos vendo, portanto, é um ciclo reformista de redução da pobreza e da desigualdade, porém um ciclo lento, levando-se em consideração que a pobreza e a desigualdade eram e continuam sendo imensas no Brasil" (SINGER, A. Os sentidos do lulismo: reforma gradual e pacto conservador. São Paulo: Companhia das Letras, 2012, p. 195). 
isso, a promoção da justiça social exige a expansão das capacidades humanas, isto é, garantias reais urgentes para o exercício da liberdade e da autonomia.

\section{Referências}

AMARAL, E. F. L.; MONTEIRO, V. P. Avaliação de Impacto das condicionalidades de educação do Programa Bolsa Família (2005 e 2009). Dados, v. 56, n. 3, 2013, pp. 531-70.

ANDERSON, J.; HONNETH, A. Autonomia, Vulnerabilidade, Reconhecimento e Justiça. Tradução de Nathalie Bressiani. Cadernos de Filosofia Alemãa: Crítica e Modernidade, n. 17, 2011, pp. 81-112.

CACCIAMALI, M. C. ; TATEI, F.; BATISTA, N. F. Impactos do Programa Bolsa Família federal sobre o trabalho infantil e a frequência escolar. Revista de Economia Contemporânea, v. 14, n. 2, 2010, pp. 269-301.

CASTEL, R. As metamorfoses da questão social: uma crônica do salário. Tradução de Iraci Poleti. $8^{\mathrm{a}}$ ed. Petrópolis: Vozes, 2009.

CASTRO, J. A.; MODESTO, L. (Orgs.). Bolsa Familia 2003-2010: Avanços e desafios. Brasília: IPEA, 2010.

GOMES, S. S. R. Notas preliminares de uma crítica feminista aos programas de transferência direta de renda: o caso do Bolsa Família no Brasil. Textos \& Contextos. Porto Alegre, v. 10, n. 1, 2011, pp. 69-81.

HABERMAS, J. Legitimationskrise im Spätkapitalismus. Frankfurt am Main: Suhrkamp, 1973.

HONNETH, A. Philosophie als Sozialforschung. Zur Gerechtigkeitstheorie von David Miller. In: __. Das Icb im Wir. Berlin: Suhrkamp, 2010.

MARIANO, S. A.; CARLOTO, C. M. Gênero e Combate à Pobreza: Programa Bolsa Família. Revista Estudos Feministas, v. 17, n. 3, 2009, pp. 901-8.

MEDEIROS, M.; SOARES, F. V.; SOARES, S.; OSÓRIO, R. G. Programas de Transferência de Renda no Brasil: impactos sobre a desigualdade. Brasília: IPEA, 2006.

MEDEIROS, M.; BRITTO, T.; SOARES, F. Transferência de renda no Brasil. Novos Estudos - CEBRAP, n. 79, 2007, pp. 5-21.

MILLER, D. Principles of Social Justice. Cambridge, MA: Harvard University Press, 2001.

MOORE Jr., B. Injustiça: As bases sociais da obediência e da revolta. Tradução de João Roberto M. Filho. São Paulo: Brasiliense, 1987. 
NOBRE, M. Imobilismo em movimento: Da abertura democrática ao governo Dilma. São Paulo: Companhia das Letras, 2013.

NUSSBAUM, M. Women and Human Development: The Capabilities Approach. Cambridge, UK: Cambridge University Press, 2000.

. Creating Capabilities: The Human Development Approach. Cambridge, ma: Belknap, 2011.

O'CONNOR, J. The Fiscal Crisis of the State. New Brunswick/London: Transaction Publishers, 2002.

SINGER, A. Os sentidos do lulismo: reforma gradual e pacto conservador. São Paulo: Companhia das Letras, 2012.

ROCHA, S. O programa Bolsa Família: Evolução e efeitos sobre a pobreza. Economia e Sociedade, v. 20, n.1, 2011, pp. 113-39.

TAVARES, P. A. Efeito do Programa Bolsa Família sobre a oferta de trabalho das mães. Economia e sociedade, v. 19, n. 3, 2010, pp. 613-35.

SEN, A. Desenvolvimento como liberdade. Tradução de Laura Teixeira Motta. São Paulo: Companhia das Letras, 2000.

A ideia de justiça. Tradução de Denise Bottmann e Ricardo Donelli Mendes. São Paulo: Companhia das Letras, 2011.

SILVA, M. O. S.; LIMA, V. F. S. A. (Orgs.). Avaliando o Bolsa Familia: unificação, focalização e impactos. São Paulo: Cortez, 2011.

SUPLICY, E. M. O direito de participar da riqueza da nação: do Programa Bolsa Família à Renda Básica de Cidadania. Ciência \& Saúde Coletiva, v. 12, n. 6, 2007, pp. 1623-28.

Renda de cidadania: A saída é pela porta. São Paulo: Cortez, 2013.

Recebido em 12.04.2014

Aceito em 10.06.2014 